\title{
Comparative Research on the Body Language of Chinese and English during Cross-cultural Communication
}

\author{
Wenjing Sun \\ Zaozhuang University \\ Zaozhuang, Shandong, China
}

\begin{abstract}
Since people come from different cultural backgrounds, the non-verbal communication is very important. Body language is an important part of non-verbal communication in cross-cultural communication. This paper firstly introduces the definition of body language. And then, it concludes the function of it. At last, the author analyzes the body language of English and Chinese in cross-cultural communication. which includes five aspects of the different personalities of the English and Chinese language and common comparative analysis from the posture, gestures, facial expressions, eye contacts, and tactile movement.
\end{abstract}

Keywords-nonverbal communication; body language; intercultural communication

\section{INTRODUCTION}

Language with the help of words becomes an important tool for human beings to express their ideas and feelings and to communicate with each other. Could it achieve the purpose of communication if without the help of words or speeches in the process of communication? The answer is yes. Language is not the only communication means. Researches show that the information exchanged through verbal communication account for 35 percent of the total amount of information, the rest is done with the help of expressions, postures, movements and other non-verbal forms. These communication means such as gestures and postures are called body language.

\section{ThE DEFINITION OF BODY LANGUAGE}

There are many kinds of definition of body language. Experts define it in different perspectives and different ways. Some of them will be exhibited later with the purpose of help understand clearly what body language is. Julius Fast in his book body language gives the following definition, "body language can include any non-reflexive and reflexive movement of a part or all of the body, used by a person to communicate an emotional message to the outside world" (Fast 1970:11). Fast defines it in a broad sense. In addition to the commonly recognized aspects, for example, gestures, posture, facial expressions, eye contact, physical appearance and touching, he also comprehends silence, sitting arrangement, space and orientation. Webster's new world dictionary (the third edition) defines body language as "gestures, unconscious bodily movements, facial expressions, etc., which serve as nonverbal communication or as accompaniments to speech". The dictionary also gives another word which is similar to body language, that is, Kinesics. It is definede as "to systematically study nonverbal body actions (such as blush, eye contacts, etc) and communications." Burgoon and Saine said: "Body language is not conveyed through words. It is a kind of man's social attributes and behaviors, which are issued by the deliverer and received by the receiver purposely". (Burgoon and Saine, 1978)

In a word, body language is a series of body movements, which means to express intention and convey cultural information. In addition to the verbal communication, people are often accompanied by various body movements such as eye contact and gestures and so on. Body language as a supplementary means of language expression, formed a special system of notation, which needed the delivers to communicate with the receiver in a certain context, and follow the same rules of communication to communicate with each other.

\section{BODY LANGUAGE AND CROSS-CULTURAL COMMUNICATION}

Body language is a series of complete, clear, patterned symbols formed in a certain cultural context. Therefore, body language which is like the verbal language is the result of cultural acquisition, and an important part of culture. Cultural environment is different, so the form of body language and the meaning of representative also have certain differences. The English-speaking countries belong to the sea civilization and advocate freedom and form a culture of dispersion. So the body language of English-speaking countries has the characters of discreteness. For example, English speakers taboo the physical contact between strangers. As an agricultural civilization, China has lived in groups since ancient times, forming an aggregate cultural pattern. Therefore, Chinese physical behaviors have the characteristics of polymerization. For example, two unfamiliar people go shopping, hand in hand; walk side by side, the Chinese feel normal, and the English-speaking people seem to be incredible. In cross-cultural communication, we not only need to know the other's basic body language, but also grasp their cultural characteristics to 
gap the communication barriers and avoid the unnecessary contradictions and conflicts.

When body language does occur, it may perform one or more functions. There are basically four functions in communication: expressive, supplementary, substitute and hint. The expressive function of body language refers to expressing feelings, emotions and attitudes such as anger, happiness, frustration or sadness and so on throng body movement like frowning, smiling, scratching one's head, etc. of which eye movements and facial expressions account for a large amount. Powerless verbal language may be found in some occasions and the most efficient way to complement is to add the nonverbal behaviors which will embroider on these speech acts through posture, gestures, facial movements and eye contacts, etc. This is the supplementary function of body language. In some conditions, body language is supplementary to the spoken language. But it is said that body language occurs earlier. Before language are created, human beings used a large amount of body language to show what they want to say for the purpose of cooperating with each other better and live better. That is what we said of substituting function. The last one is the hint function. The body language with hint function is similar to euphemisms which deliver inconvenient information to others through subtle, indirect and implicit forms. Tipping somebody the wink or shooting somebody a warming glance is good indication of body language.

\section{CONTRASTIVE STUdy OF BOdy LANGUAGE IN CROSS-CULTURAL COMMUNICATION}

About fifty years ago, Edward T. Hall said that "culture is communication and communication is culture." The true meaning beyond his words is culture influences communication and much of the meaning in our interaction with others relies on the cultural backgrounds of the communicators. However, different countries have different cultures. Therefore, the means of people's communication is different from countries.

\section{A. Different Personalities in Chinese and English of Body Language}

1) Posture: Posture refers to how people position their body, including sitting, standing, kneeling, lying, squatting and so on. Let' $s$ take squatting for example. In English speaking countries, people think it is difficult for them to keep balance if they squat, so they always sit directly on the ground or even kneel. Even though they have to squat on some occasions, they have different squatting posture from Chinese people. They will land on both toes or one foot on toe and the other on heel. But in China, it is common for you to see people squatting. People in northern villages always squat to eat though chairs are just beside them, which is incredible in foreigner eyes. The Chinese often squat with both feet on the ground and toes pointing outwards. The performance of teachers and students in Chinese and English classes also form sharp contrast. English teachers like to walk around or even sit on the desk when teaching to interact with students. Their intentions are to create a relaxed atmosphere and allow students to learn in an atmosphere of equality and freedom. But Chinese people think it is impolite and indecent. Chinese teachers always stand on the center of the platform to teach students. Only when discussing, they will come down to the students to communicate with them. It is conservative and rigid from foreigners opinions and they also concern it is not good for improving students' learning enthusiasm and developing their thinking.

2) Gestures: Gestures refer to conveying one's ideas by hands and fingers movements. Gestures are used very often in our daily life. A misinterpretation of gestures can lead to unexpected troubles and negative feelings in cross-cultural communication. Liu Huanhui in his book Basic principles of verbal communication noted "There are four types of gesture language: description, simulation, symbol, coordination." professor Deng Yanchang give us some drawings and examples about gestures to explain the diversity of gestures in Chinese and English cultures. One is the same gestures in two cultures with different meanings. For example, people draw a circle with index finger at the temple, it means somebody is going crazy in English culture, while in China, it means somebody is reckoning on things. The second type is different gesture with the same meaning.

3) Facial expression: Facial expression is an important part of body language. For example, when people feel fearing, they will open their eyes wide with an open mouth. Happiness is almost universally expressed by smiling or laughing. But it also varies in every culture with its unique social rules. In china, smiling has a lot of meaning. When two people meet for the first time and shake hands with smile on their face, it shows friendly. When people show thanks for providing help with smile, this is a smile of gratitude. Facing the apology of others and smile is the understanding. The way to understand the true meaning of smile is according to the certain context. It is incredible in English speaking countries' people eyes. An Englishman accidentally tipped over the plate while the Chinese smiled at him, which cause him angrily and think It as a mockery of his embarrassment. In fact, the Chinese just smile to show that it does not matter and not worry about it. It is these subtle expressions that lead to misunderstandings and contradictions. So how important the facial expression is in cross-cultural communication.

4) Eye movement: "The eyes are the Windows of the soul." eyes can convey fertile emotions. There are many phrases in English about eyes. For example, have a sharp eye, drop one's eyes, make eyes at sb. And so on. In English culture a lot of value is placed on direct eye to eye contact. If a person does not look at them in the eyes they feel he dislike them and think it is impolite, he is not interested in what they are saying or he is trying to deceive them. They believe "never trust a person who does not look you in your eyes". But in China, considering the polite rule, Chinese avoid looking directly at each other for a long time. 
5) Tactile movement: Tactile movement refers to conveying or exchanging information through the contact of the body. In interpersonal communication, shaking hands, hugging and kissing are frequently used in body contact. In cross-cultural communication, it is necessary to understand the differences between the English and Chinese countries in order to better understand and communicate. In English, there is very little physical contact, and in public, when two people meet, they hold each others hand, and then release it and back away from it. A hug is usually reserved for someone close to you with a kiss on the cheek. Only family members can kiss tightly or intimately. In China, two people don't usually hug in public, but with a handshake. They shake hands at the same time their bodies will come to approaching each other in order to show their respect for each other. This is very different from English-speaking countries. In public, the Chinese generally do not hug or kiss, and they always shake hands to show friendly. With the development of society, young people and couples in China will hug or kiss in public to express their affection for each other. This is the difference between two different cultures. In intercultural communication, we must fully grasp the differences of tactile movement to avoid the communication barriers caused by cultural differences.

\section{B. Common Personalities in Chinese and Western Culture}

Although the body language of the English and Chinese has their own characteristics, there are also some similarities. Some body language has the same expression and meaning, and is understood by people of different countries, nationalities and cultures. The following are the similarities analysis of the body language in Chinese and English from five aspects.

1) Posture: Due to the differences of values and traditions, there are many differences between Chinese and western countries in posture such as squatting, standing and walking, but in some poses, they are similar. Take sitting for example, When people are interested in someone or something, people like to move forward in order to get closer and closer. When people are not interested in something, their body will lean back involuntarily. These postures have some universality, and they should be handled flexibly in the context of cross-cultural communication.

2) Gesture: Although there are many differences between the English and Chinese language, there are many similarities. Many gestures that take place above the head have no differences. For example, raising one's hands to wave in the distance means "goodbye" or the greetings, this kind of hand movement is commonly used in the English and Chinese countries, which will not cause conflicts and misunderstanding. When talking to people, one is constantly looking up at the watch, this gesture in an English and Chinese culture is a more subtle way to tell each other that they are busy doing other things and try to end the conversation as soon as possible.
3) Facial expression: Facial expressions are largely determined by innate genetic factors that are common to all humans. Blushing is a sign of shyness and often associated with marital love. In the English and Chinese countries, when one is sad or disappointed, his face is the same, that is, keeping mouth shut, the chin drooping, eyes looking down, and face is pulled.

4) Eye movement: Eye movement plays an important role in expressing emotions. Like facial expressions, eye movement to a large extent also depends on human congenital genetic factors, the difference lies mainly in the English countries in the length of time of their watching and the frequency. For example, when facing the opposite sex, to convey love and affection, always look directly at each other with tender and affectionate eyes. Try to reduce the eye contact when you're feeling awkward.

5) Tactile movement: Tactile movement is very different in English and Chinese countries on the aspect of frequency, but the expression of love, hate, love and revenge is accompanied by Tactile movement. With the development of Chinese society, Chinese and western communication is frequent and people's minds gradually westernized, so young people and couples in China will also hug or kiss in public in order to express the affection of love.

\section{CONCLUSION}

With the increasing frequency of exchanges between countries in the world, the culture is constantly learning and penetrating, and the body language is constantly being updated and improved. In intercultural communication, body language is valued by its concise, lively and vivid features, which are widely used in daily life and international communication. In intercultural communication, we should carry out a thorough and careful study of the body language of the two sides and master the initiative of communication to avoid all kinds of awkwardness and misunderstanding due to cultural differences.

As an important part of communication, body language is closely related to culture. Combining the research of body language communication rules with different cultures, it can better eliminate the communication interference caused by cultural differences, improve the communication effect, and ensure the smooth progress of intercultural communication. At the same time, the knowledge of body language of different cultural circles also helps people of different nationalities communicate and understand each other, and reduce the frictions caused by cultural differences between different ethnic groups. Through the comparative analysis of English and Chinese body language, we understand the nonverbal communication between two cultures, the similarities and differences, can effectively avoid because these nonverbal differences of cultural misunderstanding and cultural conflict. Research perspective of cross-cultural communication between English and Chinese body language of the country, not only can enhance the ability of language communication and nonverbal communication, avoid the communication barriers and conflicts, and to enrich the 
culture of the two kinds of culture background, on the cultural development of various nationalities and the harmony of the world play an important role.

\section{REFERENCES}

[1] Burgoon, J.K. and Saine, T. The Unspoken Dialogue: An Introduction to Nonverbal Communication, Boston: Houghton mifflin, 1978

[2] Fast, J. Body Language, New York: M. Evans and Company, Inc, 1970.

[3] Hall, E.T. The Silent Language, New York: Doubleday, 1959.

[4] Liu Huanhui, the basic principles of verbal communication, Jiangxi: Jiangxi Education Press, 1997. 